\title{
ARTICLE \\ Strength \& Conduct of Reinforced Concrete Corner Joint under Negative Moment Effect
}

\author{
Rasha A Waheeb* \\ University of Baghdad, Department of reconstruction and projects, Civil Engineering, NTNU, Trondheim, 7491, \\ Norway
}

ARTICLE INFO

Article history

Received: 20 August 2021

Accepted: 1 November 2021

Published Online: 4 November 2021

Keywords:

Concrete design

Strength materials

Reinforced corner joint

Structure

\begin{abstract}
The aim of our study is to reveal the effect of steel reinforcement details, tensile steel reinforcement ratio, compressed reinforcing steel ratio, reinforcing steel size, corner joint shape on the strength of reinforced concrete Fc' and delve into it for the most accurate details and concrete connections about the behavior and resistance of the corner joint of reinforced concrete, Depending on the available studies and sources in addition to our study, we concluded that each of these effects had a clear role in the behavior and resistance of the corner joint of reinforced concrete under the influence of the negative moment and yield stress. A study of the types of faults that can be reinforced angle joints obtains details and conditions of crushing that are almost identical for all types of steel reinforcement details and the basic requirements for the acceptable behavior of reinforced concrete joints in the installations and the efficiency of the joint and this may help us to prepare for disasters, whether natural or other, as happens with tremors The floor and failure that may occur due to wrong designs or old buildings and the possibility of using those connections to treat those joints and sections in reinforced or unarmed concrete facilities to preserve the safety of humans and buildings from sudden disasters and reduce and reduce risks, as well as qualitative control over the production of concrete connections and sections free from defects to the extreme.
\end{abstract}

\section{Introduction}

In many structures, the continuity of two adjacent sides is necessary even if it is related to an angle. The link resulting from this confluence is expressed as the angle compass. Concrete corner joints are found in many different structures such as retaining walls, bridges and building structures. They are also found in hydraulic structures such as ground and elevated reservoirs (flumes) and culverts. The design of the straight ribs meeting at the junction can be carried out by any structural engineer, while the information is incomplete about the design of the junction area in which the moments are greatest relative to the junction and that the sudden change in the

\footnotetext{
*Corresponding Author:

Rasha A Waheeb,

University of Baghdad, Department of reconstruction and projects, Civil Engineering, NTNU, Trondheim, 7491, Norway;

Email: dr.engineerana2018@gmail.com
} 
direction of the ribs generates high local stresses as shown in Figure 1 and 2.

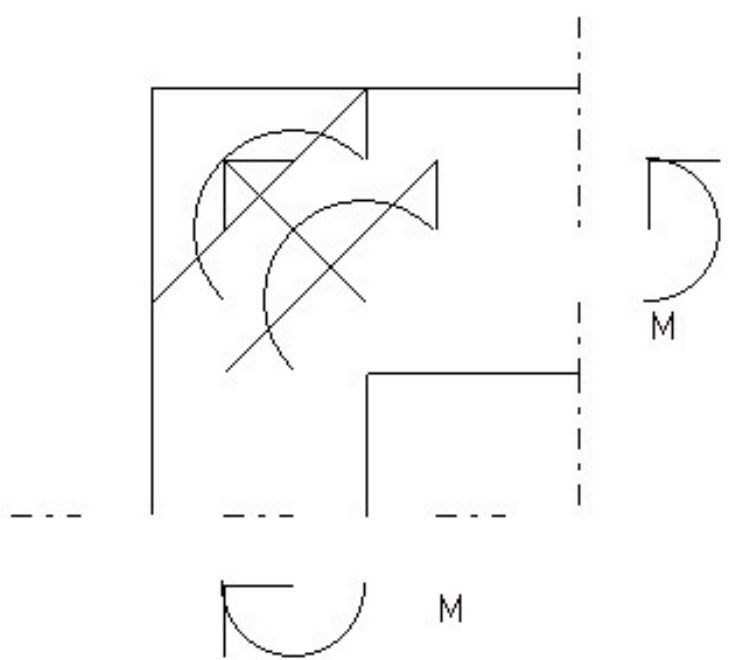

Figure 1. Tensile stresses at sections perpendicular to the diameter of the joint

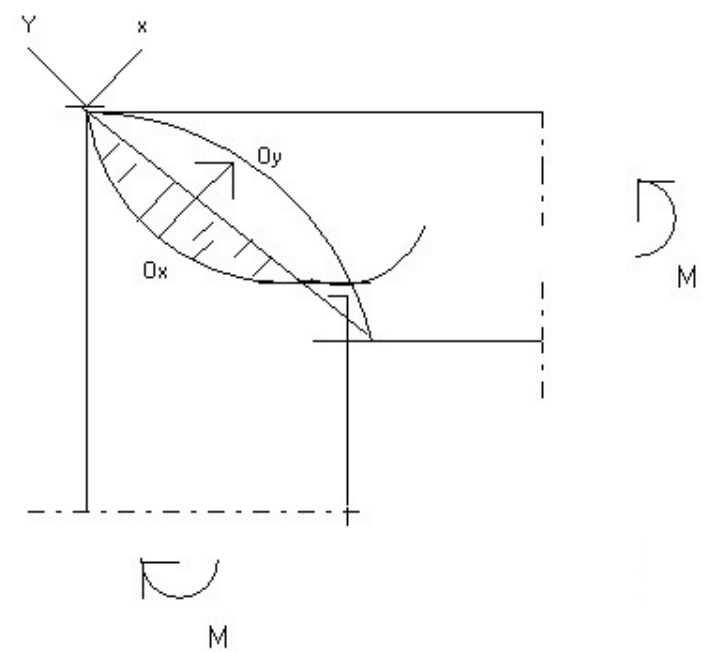

Figure 2. Diagonal stresses of an angle joint subjected to a positive torque

Surprisingly, until recently, little attention has been paid to design angle joints in reinforced concrete structures. After 1965 this situation changed and there was a wide interest in studying this point. The reason for this change was conducting a preliminary study in Sweden on an angle connection in the bridge supports. This study proved that the reinforcement details were not designed correctly, causing failure at one third of the design value. These details were lacking in Sweden and in other parts of the world at that time. Numerous experiments were conducted to find alternative rebar details of good efficiency. The researchers conducted tests on all types of armaments that were known at that time and noticed that most of them were inefficient.

The difference in the details of the rebar and the angle of the joints are important factors that affect the final value of the joints as well as affect the efficiency of the joints. The difference in the size of the joint is another factor that greatly affects the final critical value of the joints. These previous factors were not considered in the design. Corners may be subjected to closing moments, which are subject to tensile stresses at the outer corner of the corner, or opening moments, which cause tensile stresses at the inner corner. The latter kind of moment may cause more detailed problems. Opening joints can be found in water tanks with retaining walls, open channels, bridge abutments, high elevations due to the influence of wind, frame structures, etc., on the other hand, the closing joint can be found in hinged and fixed frames and underground water tanks.

Accordingly, the researchers are interested in opening the angle continued their research in an attempt to improve the efficiency of the available reinforcement details, while the researchers interested in closing the angle focused their efforts to find ways to design the joint as a single unit. To study the shear strength of the junction. In another study by ${ }^{[1]}$ on the effect of using (FILLET) at the inner corner of the joint or cutting the inner corner as shown in Figure 3 and 4 on the resistance and behavior of the joint. Pressure steel reinforcement. ${ }^{[1]}$ also studied the effect of pressure steel reinforcement.

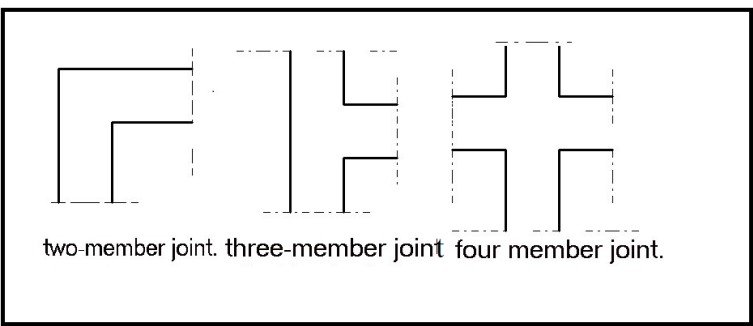

Figure 3. Types of beams column joint

They confirmed the results were presented for an experimental program previously related to the effect of reinforcement on the behavior of the angles exposed to the load at the moment of opening ${ }^{[2]}$. The reason behind this is the damages observed in the coalmine. Three full-size samples were tested with different types of reinforcement in the joint. The first sample has characteristics similar to the current structure. The other two samples were visualized and tested respectively, and each was detailed according to the observations made during the testing of the previous sample. The failure method and the reinforcing strains that were measured in each case are 
discussed.

Explored the effects of slab corners on torsional behavior of circumferential beams in buildings with reinforced concrete beams ${ }^{[3]}$, especially in the case of column loss. Several torsional tests have been carried out on the end beams, and a comparison has been made with and without ceilings, Subsequently, physics-based numerical models were developed, based on the test results, to verify the effect of changing slab parameters, such as thickness and strength ratio, on torsional capacitance. The samples have shown that the presence of reinforced concrete slabs can increase the torsional strength of the circumferential beams by the same amount to $97 \%$. The improvement came first from the angle of the slab, which was a set of compressive struts. And this effect increases with increasing thickness of the slab. It has also been observed that the angles of the plates tend to offset the torsional failure (which occurred at the twisted beam near the armature) to approximately one beam depth. The negative contribution is likely to lead at the bending moment to strengthen the slab along the edges and enhance the overall structural strength.

Concluded in their empirical and analytical study on the effect of reinforcement details ${ }^{[4]}$, confining, joint size, and joint angle on the efficiency of frame joints, and the comparison between closed and open joints. Experimentally, samples were tested for a total of 11 samples under the influence of vertical load. All samples were tested to failure and behavior was fully monitored. In addition, a nonlinear analysis of the 3D finite elements was generated using ABAQUS software and the experimental results were verified to give design recommendations for those structural element.

The structural behavior of simple structural members such as beams and columns is usually fixed in traditional designs but on the other hand, the details, strength and behavior of corner joints, especially those subject to opening moments as in the case of cantilever supporting walls, bridge abutments, ducts, cabinet structures and gate frames, are not specified, Detailed and final. Corner reinforcement details may play a major role in influencing the structural behavior of a joint further if joints or corners are opened.

Few studies have been done on frame joints to determine joint details, which may serve the purpose of strength requirements, limited cracking, ductility and simplicity of construction, and these details may vary from code to code.

The rebar must be laid in such a way that the joints perform the basic requirements. The joint must be able to withstand the calculated failure in its adjacent cross sections, because it does not limit the bearing capacity of the frames. Also, the rebar scheme in the joint must contain the necessary flexibility, so that The force can be redistributed without brittle failure in the joints, the width of the kerf at the corner must be limited to acceptable values of the working load level, and the rebar parts must be easy to manufacture.

The failure of the reinforced concrete joint may be due to several reasons such as bevel tension crack, split fracture, failure when producing steel reinforcement, failure due to concrete cracking and installation failure.

It is found that Rebar sections stipulated in the then Swedish regulations for the design of frame corners in concrete civil defense shelters are rather complex which makes it difficult to implement them correctly ${ }^{[5]}$. Therefore, a simpler method was developed, according to which all reinforcing bars are cut inside the corner area. The aim of his study was to evaluate a new design proposal and to determine whether it would be appropriate to replace traditional steel rebar sections with the new type. Eight full-scale tests were conducted for tire angles subject to negative critical moment (angle closing). The parameters differed in the tests which are the details of the rebar, the ratio of the reinforcement, the type of reinforcement and the composition of the reinforcing bars. Finite element analyzes, with material models based on nonlinear fracture mechanics and plasticity, have been performed for frame angles with new and traditional rebar detailing. The effects and weakness of the masonry joint, the interaction between the reinforcement and concrete, and the mechanical properties of the rebar were also investigated using this method. It was estimated that tests and analyzes showed that the details of conventional and new steel rebars for practical purposes are equivalent when using a low reinforcement ratio; They note that this is also the case when a high booster ratio is used. Accordingly, this work supports the idea that the new detail is suitable for use in place of traditional rebar detailing. The analyzes showed that the bond slip relationship affects the rigidity of the structure and that it also affects the overall deformation capacity. However, its effect on the maximum load capacity was found to be minimal. Moreover, it has been shown that the mechanical properties of rebar can have a significant influence on the deformation ability; After the initial cracking, the weakness of the masonry joint has little effect on the structural behavior of the tire angle.

Found in their experimental study and laboratory tests of both strength and behavior in obtuse angles of reinforced concrete under the bending holes of five of the thirteen total samples with an obtuse angle of 145 degrees 
${ }^{[6]}$, the tested corner samples had different reinforcement details; in the rest of the thickness or length of each of the adjacent members which were Various patterns of observed crack and failure and absolute strengths adding inclined bars to rings at joints have been found to significantly improve bending efficiency. The effect was to change the hardness, Neighboring members have a role in greatly improving efficiency and as a result gradual change in the prevailing and traditional methods of failure.

Studied special samples using glass fiber reinforced polymers as the main reinforcement in concrete structures ${ }^{[7]}$; he found an attractive option for structures in aggressive environments. In his study, he emphasized that the concrete knee joints are joints where the crossbar and the column end at the joint. The application of GFRP bracing in the knee joints may be problematic given the weak link at the reinforcing curve. This is critical because there is a risk of possible premature joint failure due to penile rupture, regardless of adjacent organ designs. The behavior of GFRP-reinforced knee joints has not been studied before. The presented experimental program consisted of eight full-size samples that were tested under monotonous sealing loads. The variables that have been studied are the effect of varying reinforcement ratio, the effect of confinement stirrups in the joint, and the effect of angle geometry. The eight samples are divided into two groups, confined and unconfined samples. Of the eight samples, two were designed with variable geometry to include the internal chamfer. The test results indicate that the increase in the reinforcement ratio improves the force efficiency while changing the failure mode directly: failure due to rupture of the rod is prevented with the increase in the reinforcement ratio and is caused by the failure of the inclined bracket. The addition of a confinement stirrup increased the absolute force as well as the maximum deflection. The effect of changing the angle geometry has a slight effect on the strength of the sample; However, brittle failure of the joint was prevented. Further studies are to be conducted including different confinement techniques, different FRP types and suppliers, as well as different types of loading such as opening moments and load reflections.

In their study ${ }^{[8]}$ found Frames are used in special critical moments of reinforced concrete as part of seismic strength resistance systems in designed buildings to resist earthquakes. Beams, columns and beam-column joints Moment tires are proportional and detailed for resistance, bending, axial and shear actions produced as a building, Oscillates through multiple displacement cycles during force earthquake, earthquake. Special proportion and Details of requirements lead to a tire that can resist Strong earthquake shaking without significant loss of hardness or strength. These moment-resistant tires are called "Special Moment tires" due to these additional requirements, which improves seismic resistance compared to less, finely detailed medium and regular moment frames. The concepts of rebar for tires at the crucial special moment are concrete It was introduced in the United States beginning around 1960 (Bloom, Newmark, and Corning 1961). Its use at that time was mainly in Designer appreciation of installations, as it was not until 1973 that The Uniform Building Code (ICBO 1973) first requires the use of Special frame details in areas with high seismicity. The Closer to detail requirements are remarkably similar to those In place today.

They began their studies ${ }^{[9]}$ as a core part of a collaborative project aimed at (NEES-Grand Challenge) that aims to assess collapse risks and develop mitigation strategies for older type RC buildings. The behavior of unreinforced joints under earthquake loads was of interest in this study, and they conducted extensive analytical and experimental investigations to simulate the gradual collapse of old RC buildings and create fragile collapse curves.

This study describes an experimental program that develops instantaneous rotation; the relationships are similar to the backbone relationships of unreinforced joints for simulations of sub-assemblies of beam columns and prototype building frames. To predict the shear strength, two models of shear strength have been developed by quasi-experimental and analytical approaches, and a new working model has been developed. Four full-scale testing and unreinforced concrete angle joint samples were performed to verify proposed shear strength models and to provide standard information for the development of unreinforced backbone relationships for external joints. The evolving spinal relationships were validated by accurate reproduction of the load displacement responses of four external joint samples and four other planar samples, and the external joint samples were taken from the literature. As an introduction to progressive breakdown analysis. For older type RC buildings, nonlinear dynamic simulations were performed on three virtual building frameworks using the developed backbone relationships.

\section{A. Resistance requirements for concrete structural buildings and requirements for buildings and structures resistant to earthquake loads:}

Seismic loads (and horizontal loads in general) can be resisted by a number of structural systems. Among these structural systems, the following systems can be 
mentioned:

1) Frame System

This system consists of columns and beams connected to each other by rigid joints, meaning joints that bear a bending moment. This system is made of steel (steel) or reinforced concrete. And the reinforced concrete frame must be ductile to secure large deformations before collapsing to dissipate or reduce the energy of the earthquake and make the collapse (if it occurs) safe.

2) Wall system

This system consists of vertical load bearing walls. These walls can be executed from built stones (or from non-reinforced materials in general), and the connection of the wall with the ceiling in this case is hinged joints, and these load-bearing walls can also be executed from reinforced concrete, and the connection of the wall with the ceiling in this case With rigid compasses, the wall in this case is called a shear wall.

3) Mixed systems of frames and shear walls

This system comprises a group of frames and another group of shear walls, which together share in resisting horizontal loads in their stiffness proportions.

4) Sufficient frame system

This system is made of steel in particular, where the frame system is lined with appropriate elements, after which the frame is transformed into a kind of truss. It can also be implemented from reinforced concrete.

5) Prefabricated Establishments System

This system consists in particular of panels in the form of load-bearing walls and other panels that are placed horizontally and act as slabs, and this system is usually implemented from prefabricated reinforced concrete. The connection between the wall panels and the slab panels in this system is by hinged joints practically that cannot withstand bending moments. The load-bearing walls in these structures are studied to resist bending moments as cantilever shear walls that operate vertically with the condition that they do not have any tensile stresses in any section. In both vertical and horizontal directions.

\section{B-Requirements for buildings that will withstand horizontal loads in the frame system (columns and beams)}

It is preferable that the height of the reinforced concrete building not exceed (7) seven floors (floors), including the floors of the basements, if any.

The set of columns that will make up the frame should lie on one straight line.

The tires shall be shaped according to the previous condition in both directions.It is preferable to use frequent spacing between columns (using the modular reinforced concrete frames)

What is stated in this regard in terms of design requirements and armament details in (the Arab code for the design and implementation of reinforced concrete structures) of the Arab code shall be taken into account.

Columns:

Column design: Column design is prohibited assuming that there are spandex (plastic) joints in them.

Connection: Reinforcing steel joints with columns and beams are implemented in a way that ensures the transmission of bending torques between them according to the requirements of the Arab design code, and for reinforced concrete columns, reinforcing bars are installed in the beams or connections to ensure the durability of the connection.

Reinforced Concrete Columns: Concrete Columns shall be closed. Circular canes (with hooks) are used for circular poles, noting that spiral bracelets can be used to increase resistance.

Elongated frame columns: The length of the frame columns is designed in full compliance with all the requirements stipulated in the Arab code for the design and implementation of reinforced concrete structures from the Arab code.

Horizontal slabs (diaphragms):

1) Rigidity: The horizontal slabs (which act as diaphragms) are rigid within their level, and capable of transferring horizontal forces to the vertical bracing elements without subjecting them to major deformations.

2) Connecting beams (Jizan): The tiles shall be surrounded by connecting beams capable of resisting tensile or compressive forces of no less than (50) kilonewton, according to the safety parameters and requirements for stability and stability stipulated in (the Arab Code for the Design and Implementation of Reinforced Concrete Structures and the Arab Code for Steel Structures ) with special care in fixing the reinforcing bars at the corners.

3) Transfer of forces within the slabs: In the event of a sudden change in the vertical stiffening elements, such as the shift in the stiffness of columns or walls, it should be ensured that the forces transfer within the slabs, especially at the level of this change. The connecting beams surrounding these connections must be able to withstand tensile or compressive forces of no less than (100) kilonewtons, and according to the safety factors stipulated in the Arab design codes.

4) Connecting between the tiles and the vertical stapling elements: It should be ensured that solid connections are obtained between the tiles and the vertical stapling elements, by installing the slabs' reinforcing bars 
in the vertical stapling elements ${ }^{[9]}$.

\section{Methodology}

The main objective of conducting finite element analysis as samples is to extend the scope of investigations that have been conducted experimentally in the field and in the laboratory to get a better understanding of the behavior of all tested samples.

\section{Results and Discussions}

\section{Conductance and resistance of the junction reinforced concrete corner}

In many structures, continuity between two adjacent ribs is necessary even if these two ribs meet at an angle and a joint in a portal frame is the best example of this.

The internal forces generated in such a joint may cause failure inside the joint before the shaft or threshold, whichever is weaker, reaches the bearing strength.

The corner joint of the portal frame may occur in a two-way frame. The corner joint can be named as follows:

1) Two moment joint.

2) A four-member joint.

3) Three member joint.

Typical examples of these types are shown in Figure 4 in a two-sided joint, the beam torque is completely transmitted to the shaft under it. In a three-sided joint, the beam torque is distributed over the two shafts according to ratios that depend on relative stiffness.

The second type of joint is a link with four sides, in which no torque transmission may occur from thresholds to columns.

\section{Compression reinforcement}

The effect of the compression ratio of rebar on the behavior and resistance of the angle joint was mentioned in source ${ }^{[1]}$,In this source three tests were compared with each other, where the joints for these tests each contained $1 \%$ tensile reinforcing steel.

\section{Reinforcement bar size}

What was mentioned in previous studies about the effect of the size of tensile rebar on the behavior and resistance of the concrete joint is small compared to the effect of other variables mentioned ${ }^{[10]} \mathrm{He}$ was mentioned that the diameter of the tensile rebar is directly on the behavior and resistance of the joint. Figure 4 shows shape of concrete corner joint.

The reinforced corner joint subjected to loads that lead to closing the angle fails by one of the following types:

1) Flexural failure Figure 5 .

2) Bearing failure Figure 6.

3) Shear failure Figure 7.

The effect of these variables can be summarized as follows:

a- The shear strength is inversely proportional to the length of the space.

b- Shear failure load increases with increasing FC'.

c-The shear strength increases slightly when the proportion of reinforcing steel increases, and this effect can be observed especially in the joints containing a low proportion of reinforcing steel ${ }^{[11]}$.

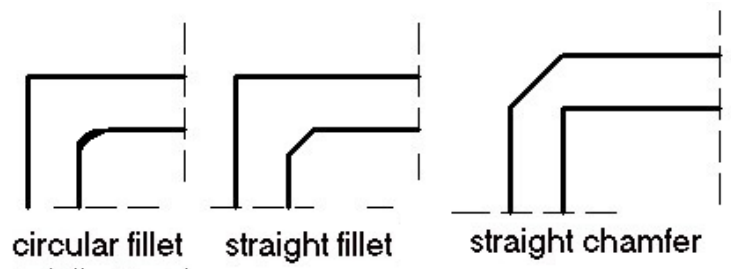

Figure 4. Types of the concrete corner joint cutting

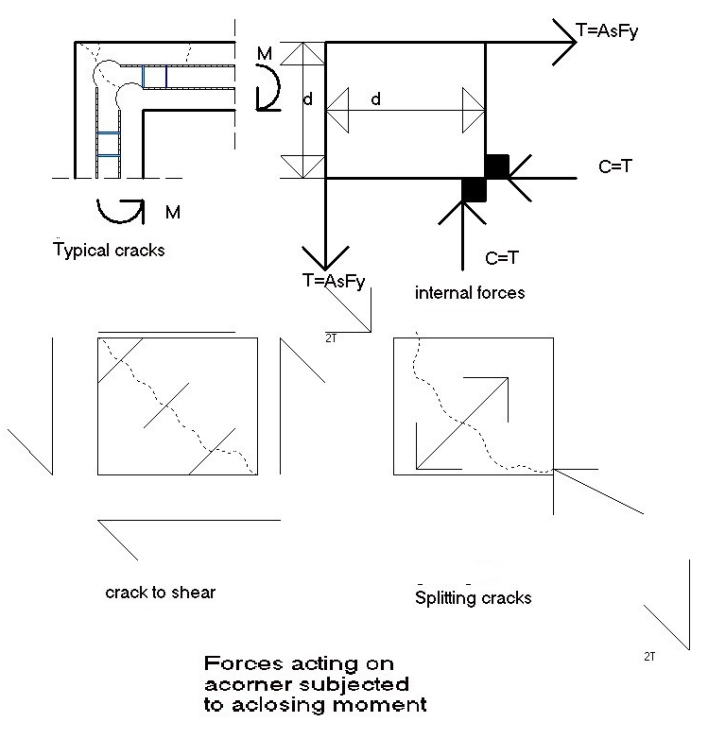

Figure 5. Force acting on the torque-locking joint
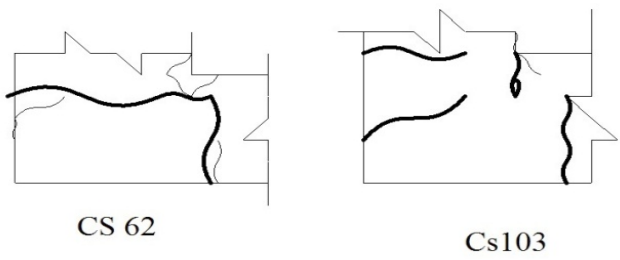

Figure 6. Typical examples of flexural failure ${ }^{[12]}$ 


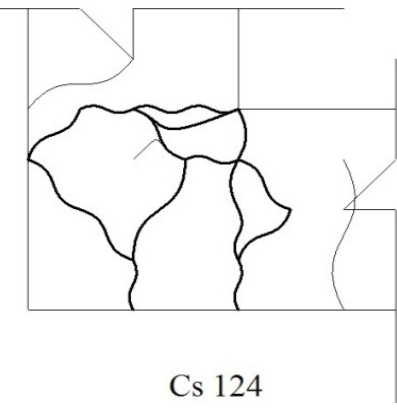

Figure 7. Typical example of loading failure

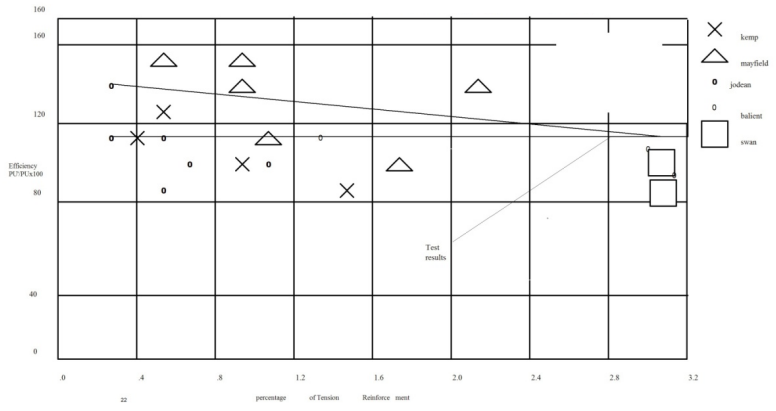

Figure 8. Relationship between efficiency and Percentage of tension reinforcement

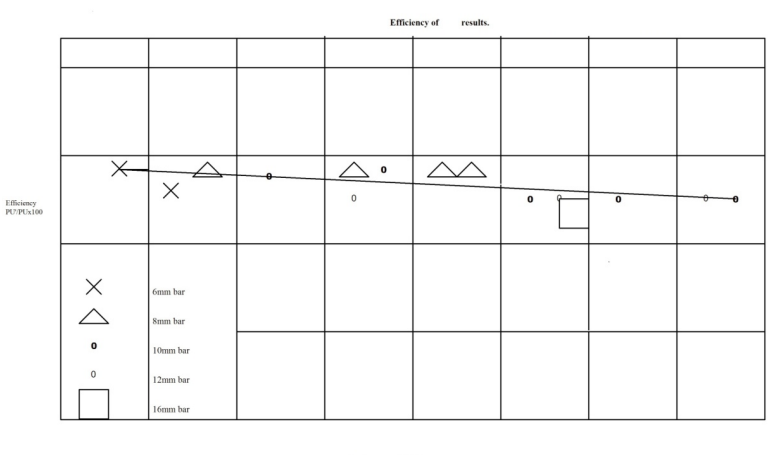

Figure 9. Efficiency of concrete corner joints used

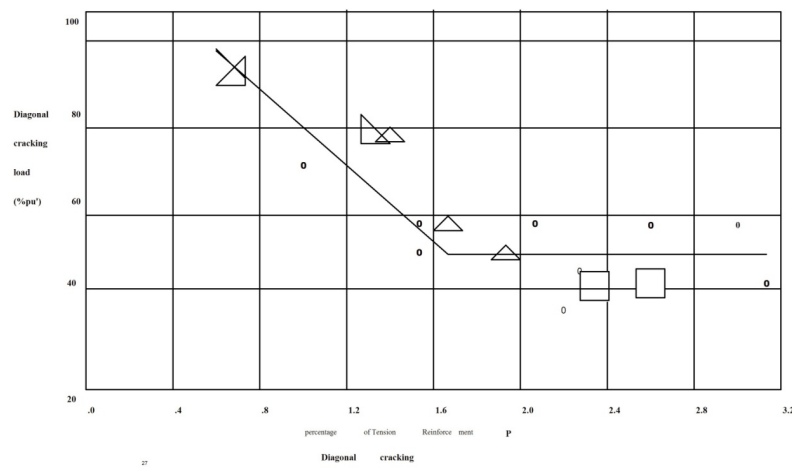

Figure 10. Diagonal cracks

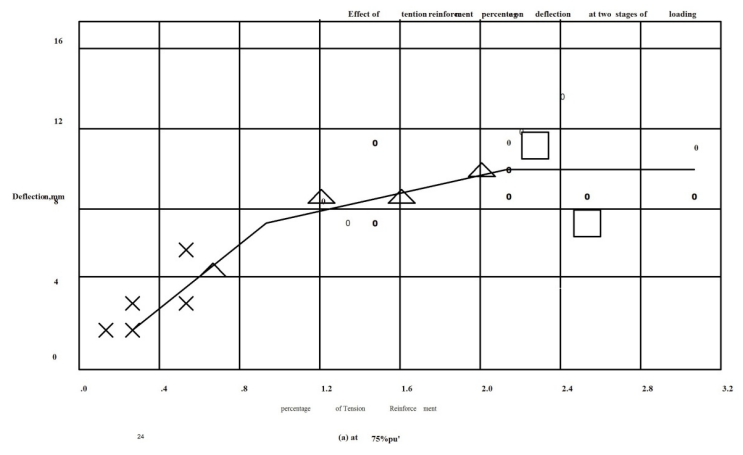

Figure 11. The effect of the tensile reinforced steel percentage on the two loading stages

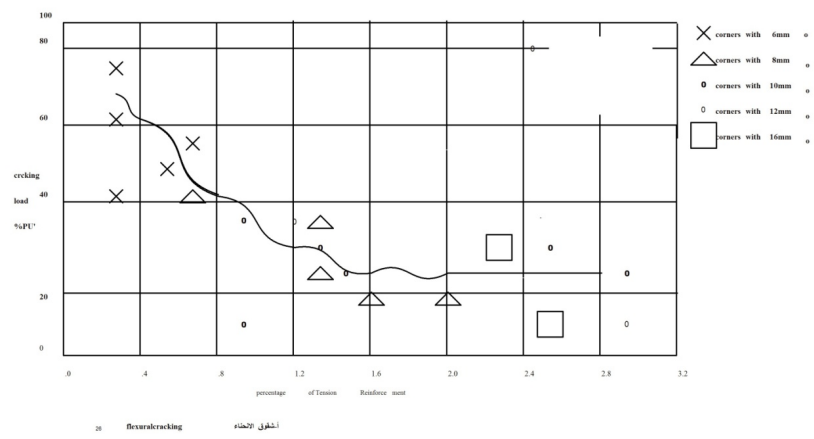

Figure 12. Effect of crack strength on corner joint

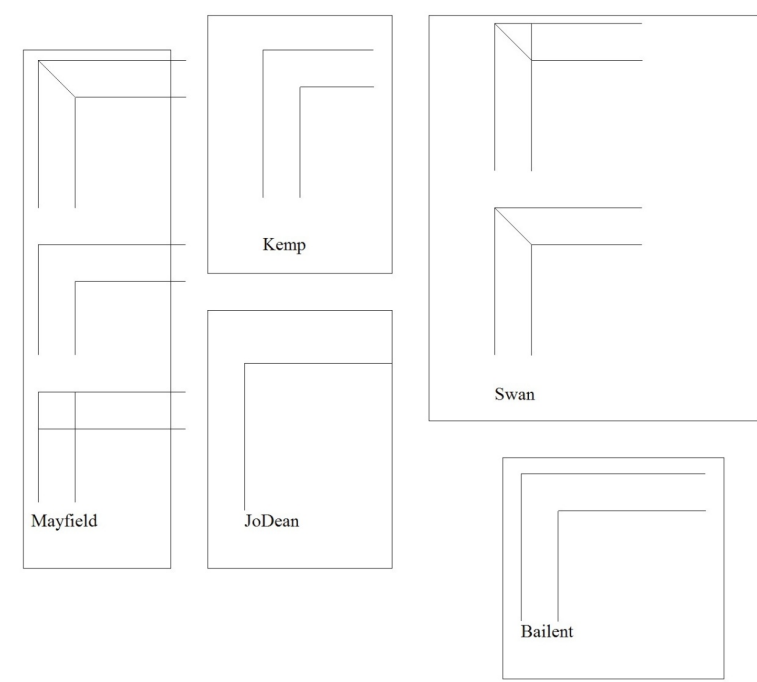

Figure 13. Details of reinforced steel according to researchers references ${ }^{[12-16]}$

\section{Conclusions}

Our study is considered the beginning of developing a model to determine the strength and behavior of joints of outer beam columns for earthquake resistance. It also 
achieves the balance, compatibility and stress properties of cracked reinforced concrete. This study can provide valuable insights. In the seismic behavior of outer column joints; it is ready to serve analytical purposes such as seismic evaluation of existing joints. This study may result in further development of the angle joints and joints in future work, and the design methods may include this approach well on the same context and format.

\section{References}

[1] Richart, F. E., Olson, T. A., \& Dolan, T. J. (1938). Tests of reinforced concrete knee frames and bakelite models. Univ. Illinois Expt. Sta. Bull, 307.5.)kemp , E.L. and Makherjee P.R.

[2] Moretti, M. L., Tassios, T. P., \& Vintzileou, E. (2014). Behavior and Design of Corner Joints under Opening Bending Moment. ACI Structural Journal, 111(1).

[3] Pham, A. T., Pham, X. D., \& Tan, K. H. (2019). Slab corner effect on torsional behaviour of perimeter beams under missing column scenario. Magazine of Concrete Research, 71(12), 611-623.

[4] Nabil, M., Hamdy, O., \& Abobeah, A. (2016). Affecting aspects on the behaviour of frame joints. HBRC journal, 12(2), 147-162.

[5] Johansson, M. (1996). New reinforcement detailing in concrete frame corners of civil defence shelters: Non-linear finite element analyses and experiments. Chalmers University of Technology.

[6] Abdul-Wahab, H. M., \& Ali, W. M. (1989). Strength and behavior of reinforced concrete obtuse corners under opening bending moments. Structural Journal, 86(6), 679-685.
[7] Sleiman, N. (2017). Tests on GFRP reinforced concrete knee-joints subjected to negative moments (Doctoral dissertation, University of Waterloo).

[8] Moehle, J. P., Hooper, J. D., \& Lubke, C. D. (2008). Seismic design of reinforced concrete special moment frames. US Department of Commerce.

[9] ACI Committee. (2008). Building code requirements for structural concrete (ACI 318-08) and commentary. American Concrete Institute.

[10] Petroski, H. (2012). To forgive design. Harvard University Press.

[11] Al-Khafaji, J. M. N. (1980). The effect of size and percentage of tension reinforcement on the behaviour of reinforced concrete (Doctoral dissertation, University of Southampton).

[12] Swann, R. A. (1969). Flexural strength of corners of reinforced concrete portal frames.2.)Mayfield, B,Kong,F.K Bennison A. and ,davis ,J.C.D.T.

[13] Kemp, E. L., \& Mukherjee, P. R. (1968). Inelastic behavior of concrete knee-joints". The Consulting Engineer, 44-48.

[14] Mayfield, B., Kong, F. K., Bennison, A., \& Davies, J. C. T. (1971, May). Corner joint details in structural lightweight concrete. In Journal Proceedings (Vol. 68, No. 5, pp. 366-372).

[15] Mukherjee, P. R., \& Coull, A. (1972). Free vibrations of coupled shear walls. Earthquake Engineering \& Structural Dynamics, 1(4), 377-386.

[16] Park, S., \& Mosalam, K. M. (2012). Experimental and analytical studies on reinforced concrete buildings with seismically vulnerable beam-column joints. Pacific Earthquake Engineering Research Center. 